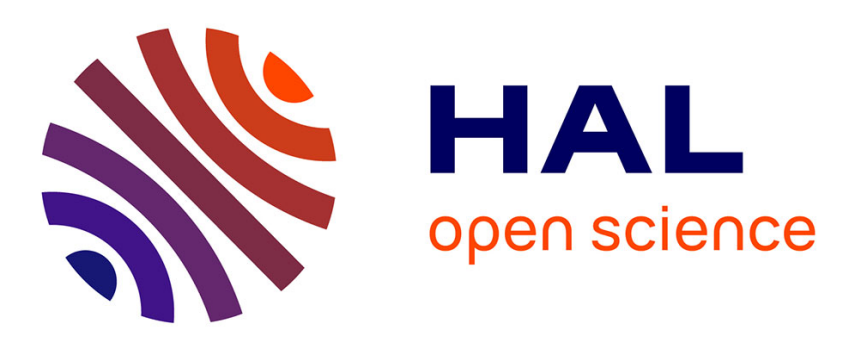

\title{
Improving the assessment of ICESat water altimetry accuracy accounting for autocorrelation
}

Hani Abdallah, Jean-Stéphane Bailly, Nicolas Baghdadi, Nicolas Lemarquand

\section{To cite this version:}

Hani Abdallah, Jean-Stéphane Bailly, Nicolas Baghdadi, Nicolas Lemarquand. Improving the assessment of ICESat water altimetry accuracy accounting for autocorrelation. 2011. hal-00628370

\section{HAL Id: hal-00628370 \\ https://hal.science/hal-00628370}

Preprint submitted on 3 Oct 2011

HAL is a multi-disciplinary open access archive for the deposit and dissemination of scientific research documents, whether they are published or not. The documents may come from teaching and research institutions in France or abroad, or from public or private research centers.
L'archive ouverte pluridisciplinaire HAL, est destinée au dépôt et à la diffusion de documents scientifiques de niveau recherche, publiés ou non, émanant des établissements d'enseignement et de recherche français ou étrangers, des laboratoires publics ou privés. 


\title{
Improving the assessment of ICESat water altimetry accuracy accounting for autocorrelation
}

\author{
Hani Abdallah ${ }^{\mathrm{a}, *}$, Jean-Stéphane Bailly ${ }^{\mathrm{b}}$, Nicolas Baghdadi ${ }^{\mathrm{a}}$, Nicolas \\ Lemarquand $^{\mathrm{a}}$ \\ ${ }^{a}$ CEMAGREF, UMR TETIS, 500 rue François Breton, F-34093 Montpellier, France \\ ${ }^{b}$ AgroParis Tech, UMR TETIS, 500 rue François Breton, F-34093 Montpellier, France
}

\begin{abstract}
${ }^{1}$ Given that water resources are scarce and are strained by competing demands, it has become crucial to develop and improve techniques to observe the temporal and spatial variations in the inland water volume. Due to the lack of data and the heterogeneity of water level stations, remote sensing, and especially altimetry from space, appear as complementary techniques for water level monitoring. In addition to spatial resolution and sampling rates in space or time, one of the most relevant criteria for satellite altimetry on inland water is the accuracy of the elevation data. Here, the accuracy of ICESat LIDAR altimetry product is assessed over the Great Lakes in North America. The accuracy assessment method used in this paper emphasizes on autocorrelation in high temporal frequency ICESat measurements. It also considers uncertainties resulting from both in situ lake level reference data. A prob-
\end{abstract}

\footnotetext{
*Phone: +33 467548719, Fax: +33 467548700

Email address: hani.abdallah@teledetection.fr (Hani Abdallah)

1 ABBREVIATIONS:

ICESat: Ice Cloud and land Elevation Satellite

GLAS: Geoscience Laser Altimeter System

RMSE: Root Mean Square Error

SDOM: Standard Deviation Of the Mean
} 
abilistic upscaling process was developed. This process is based on several successive ICESat shots averaged in a spatial transect accounting for autocorrelation between successive shots. The method also applies pre-processing of the ICESat data with saturation correction of ICESat waveforms, spatial filtering to avoid measurement disturbance from the land-water transition effects on waveform saturation and data selection to avoid trends in water elevations across space. Initially this paper analyzes 237 collected ICESat transects, consistent with the available hydrometric ground stations for four of the Great Lakes. By adapting a geostatistical framework, a high frequency autocorrelation between successive shot elevation values was observed and then modeled for $45 \%$ of the 237 transects. The modeled autocorrelation was therefore used to estimate water elevations at the transect scale and the resulting uncertainty for the 117 transects without trend. This uncertainty was 8 times greater than the usual computed uncertainty, when no temporal correlation is taken into account. This temporal correlation, corresponding to approximately 11 consecutive ICESat shots, could be linked to low transmitted ICESat GLAS energy and to poor weather conditions. Assuming Gaussian uncertainties for both reference data and ICESat data upscaled at the transect scale, we derived GLAS deviations statistics by averaging the results at station and lake scales. An overall bias of $-4.6 \mathrm{~cm}$ (underestimation) and an overall standard deviation of $11.6 \mathrm{~cm}$ were computed for all lakes. Results demonstrated the relevance of taking autocorrelation into account in satellite data uncertainty assesment.

Keywords: GLAS, LIDAR, accuracy, temporal correlation, block kriging, Great Lakes 


\section{Introduction}

Although lakes and rivers correspond to only $0.27 \%$ of the global fresh water and $0.007 \%$ of the Earth's water budget, they constitute the most accessible inland water resources available for ecosystems and human consumption.

Given that these resources are scarce and are strained by competing demands, it has become crucial to develop and improve techniques to observe the temporal and spatial variations in the water volume of lakes, rivers and wetlands to meet human needs and assess the ongoing impacts of climate change.

For this reason, most countries operate a national network of inland water level stations to collect information for water resource development. The installation and maintenance of such networks are expensive tasks that only international cooperation programs can initiate and sustain in many countries. The availability and access to data from water level stations are therefore severely limited due to a decline in the number of stations, inadequate monitoring networks, gaps in records, differences in processing and quality control, differences in datum level and differences in data policies (Harvey and Grabs, 2003; Chen and Chang, 2009). As a consequence, water resource sampling is neither spatially nor temporally homogeneous.

Due to the lack of data and the heterogeneity of water level stations, remote sensing, and especially altimetry from space, appear as complementary techniques for water level monitoring (Calmant and Seyler, 2006).

Satellite radar altimetry first appeared in 1974 with Skylab. In 1975, the GEOS-3 radar altimeter was designed to monitor ocean surfaces, followed by the SEASAT (1978) and GEOSAT (1985-1989) missions. Radar altimetry 
entered a pre-operational phase in 1992 with the satellites ERS and TopexPoseidon, followed by Envisat and Jason in 2001. All these missions were originally designed for measuring the level of the ocean through a combination of a radar technique determining the distance from the satellite to the reflecting surface and a satellite positioning technology identifying the precise location (within centimeters) of the satellite. Since 1990, the radar elevation measurements have demonstrated their relevance for inland water observation (Bercher, 2008). The application of this technique in the literature has allowed monitoring of the inland seas (Aladin et al., 2005), lakes (Birkett, 1995, 2000; Birkett et al., 2002; Crétaux and Birkett, 2006) and large rivers (Birkett, 1998; Mercier, 2001; Maheu et al., 2003).

In addition to spatial resolution and sampling rates in space or time, the most relevant criterion for satellite altimetry on inland water is the accuracy of the elevation data; therefore, many studies aimed to quantify these accuracies. Morris and Gill (1994) found a Topex-Poseidon data RMSE (Root Mean Square Error) of a few centimeters on the Great Lakes of North America. Studies over other world lakes indicated the following RMSE values: i) greater than $10 \mathrm{~cm}$ for Lake Chad (Birkett, 2000); ii) approximately $5 \mathrm{~cm}$ for Issyk Kul Lake, Kyrgyzstan; and iii) $10 \mathrm{~cm}$ for Chardarya Lake, Kazakhstan (Crétaux and Birkett, 2006). The accuracy of radar altimetry was also studied for a selection of rivers and floodplains in the Amazon Basin. Substantial errors were observed with RMSE values between $40 \mathrm{~cm}$ and 1.1 m (Birkett et al., 2002; Bercher, 2008).

In recent years, LIDAR onboard satellite also appears as a promising tool for accurate, high resolution altimetry. The Geoscience Laser Altimeter System (GLAS) ranging instrument onboard the ICESat (Ice Cloud and land Elevation Satellite) provides elevation data over all Earth surfaces. Its main 
strength is its small footprint diameter averaged over $70 \mathrm{~m}$ (Zwally et al., 2002) compared to the larger radar footprint size of $250 \mathrm{~m}$ to a few $\mathrm{km}$. This relative small footprint size is promising for inland water monitoring, especially in rivers. ICESat was launched on the 13 January 2003 and the mission stopped at 14 august 2010. It included three lasers that transmitted short pulses (4-6 ns) of infrared light (1064 nm) and visible green light $(532 \mathrm{~nm})$. GLAS used 1064-nm laser pulses to measure the heights of the surface and dense cloud and $532 \mathrm{~nm}$ pulses to measure the vertical distribution of clouds and aerosols. The 1064-nm signal was also separately filtered and digitized at $2 \mathrm{MHz}$ for detection of dense clouds and aerosols at $76.8-\mathrm{m}$ vertical resolution. The three lasers have been operated one at a time, sequentially throughout the mission. To extend mission life, the operational mode included 33-day to 56-day campaigns, several times per year. Each period has been assigned a campaign or operations period identifier, such as Laser 2a, to denote the operating laser (2) and the operations period (a) (Schutz et al., 2005). Laser pulses or shots at $40 \mathrm{~Hz}$ illuminated sites spaced at 170 -meter intervals along track over Earth's surface. The primary mission of GLAS was to measure changes in ice sheet elevation, and secondary objectives included the measurement of cloud and aerosol height profiles, land elevation, vegetation cover and sea ice thickness (Zwally et al., 2002; Schutz et al., 2005). Although less devoted to water monitoring compared to radar altimetry, these LIDAR data could also be used to observe the inland water altimetry (Urban et al., 2008).

To date, few studies assessed GLAS elevation data accuracy for inland waters. The estimated standard deviation of GLAS elevation data computed on Lake Nasser in southern Egypt range from 3 to $8 \mathrm{~cm}$ (Chipman and Lillesand, 2007). On Otter Tail County lakes (USA), Bhang et al. (2007) 
indicates differences between GLAS elevation and hydrologic station elevation ranging from 2 to $35 \mathrm{~cm}$. Urban et al. (2008) reports GLAS elevation RMSE of approximately $3 \mathrm{~cm}$ under clear conditions, $8-15 \mathrm{~cm}$ under cloudy skies and $25 \mathrm{~cm}$ under very cloudy skies on the Tapajos Rivers (Brazil).

Several problems were revealed in previous satellite altimetry accuracy studies. First, detailed descriptions of the assumptions and accuracy statistics computation are lacking. Second, most of the studies compute errors between satellite and ground data considering ground data as 'truth', or exact and free from uncertainty. Consequently, in terms of error distribution estimation, most studies only compute RMSE as an accuracy statistic, but despite its common use, RMSE is inadequate because it mixes the bias (exactness) and dispersion (standard deviation) of satellite measurements, which can have very different consequences on their final utility. Moreover, no study compares a single shot elevation value to the ground reference data; rather, studies compare reference data to an average of successive shots, consistent with the bodies of water under consideration, such as a river section or a continuous lake transect. Therefore, before accuracy statistics computation, an implicit aggregating or upscaling process, which is typically an average based on the arithmetic mean, involves successive shot elevation values that occurs at the scale of the studied water body. As a result from this aggregating process, the satellite 'measurement' is thus compared to the corresponding ground data. The use of an arithmetic average assumes that successive shots are considered as independent (Morris and Gill, 1994) and identically distributed, allowing the usual statistics computation on measurement uncertainties, such as the SDOM (Standard Deviation of the Mean).

The centimeter differences observed between satellite measurements and ground measurements and the uncertainty of both measurements can make 
the error word inappropriate to qualify the observed deviations between satellite and ground measurements. If not, how to estimate the bias (mean) and dispersion of these deviations ? To answer this question, we need to first consider the satellite and ground measurements as random variables and to verify their significant deviations by computing the uncertainty of each measurement, ground measurements and satellite measurements, at water body scale. The uncertainty of satellite measurements at water body scale can be estimated using the SDOM only if the shot elevation values are, for high frequencies, independent in time and space. If not, the correlation between successive shot altimetrical values, denoted further as autocorrelation, must be modeled and estimated. Uncertainty at the water body scale must be computed accordingly. Although infrequent in satellite elevation data, the support effect accounts for the dependence between sequential measurements in upscaling and is a typical practice used on spatial data (Chiles and Delfiner, 1999) (Atkinson and Tate, 2000). It has already been used for remote sensing data accuracy assessments (Crosson et al., 2010) and even on LIDAR data (Bailly et al., 2010).

This paper aims to i) explore the high frequencies autocorrelation in GLAS-ICESat water elevation shot data, ii) assess the consequences of this autocorrelation in the uncertainty statistics on water level estimates and iii) assess the consequences of this autocorrelation in deviations to ground station elevation data from the Great Lakes. To ensure a proper comparison, ICESat data pre-processing was first performed. It consisted of i) the exclusion of shots with waveform saturation corresponding to data near land (Baghdadi et al., 2011), ii) the exclusion of shot outliers from atmospheric disturbance, iii) the application of saturation corrections to initial elevations (Urban et al., 2008) and iiii) the exclusion of data when lake water surface 
can not be considered as flat for accuracy and deviations estimates. The autocorrelation between successive shot elevation values was first tested and modeled for each of the considered sets of shots. A set of shots consist of a GLAS transect within a Great Lake, spatially coherent with a given ground water-level station (a water body) and temporally located in the same satellite track. We thus proposed an explicative model of the autocorrelation presence. In cases of significant autocorrelation and absence of trend in transect shot data, a block kriging process (Wackernagel, 1995) was used to estimate a mean water elevation at the transect scale and its uncertainty, Finally, the ground measurements and satellite measurements and their relative uncertainties at the transect scale were estimated. By considering these two water elevation estimates as random variables, according deviations statistics (bias and standard deviations) were proposed.

\section{Study site and data set description}

\subsection{Study site}

Due to the lack of data on one of the five Great Lakes in North America, the assessment of GLAS-ICESat elevation data accuracy was assessed for the following lakes: Superior, Michigan, Erie and Ontario. One of the youngest natural features on the North American continent, the Great Lakes make up the largest surface freshwater system on Earth. Covering more than 94,000 square miles and draining more than twice as much land, these freshwater seas hold an estimated 22.7 trilliards cubic meters of water, approximately one-fifth of the world's surface freshwater and nine-tenths of the U.S. supply. A network of 52 hydrometric stations monitor the Great Lakes (25 Canadian

MEDS station and 27 US NOAA stations) for level measurement (Fig. 1). 
The Great Lakes have from 1 to $4 \mathrm{~cm}$ tides but no prevalent ocean tides. Thus, the Great Lakes are an excellent site for accuracy studies.

Here is located Fig. 1

\subsection{Data set}

\subsubsection{ICESat data}

The GLAS elevation data used in this study are the Level-2 altimetry products GLA14 and GLA01 (Release 31) that provide surface elevation measurements (land, water, etc.) and corresponding waveforms. GLA14 data also include the laser footprint geolocation with a precision smaller than $4 \mathrm{~m}$ (Duong et al., 2006). GLA01 data include waveforms that have been decomposed into multiple Gaussian distributions (Wagner et al., 2006;

Jutzi and Stilla, 2006; Chen, 2010) corresponding to 544 or 1000 samples of received power in volts at 1 ns sampling rate (see Zwally et al. (2002) for a detailed description of ICESat full waveform data). These data record the period between 20 February 2003 and 11 October 2009. In this study, 237 ICESat transects, with lengths ranging from 5 to $20 \mathrm{~km}$, containing 20,224 shots have been used (Table 1). These 237 selected transects are the set of continuous tracks of shots that are i) in a radius of $20 \mathrm{~km}$ from an available hydrometric station to avoid the influence of natural spatial lake level variations and ii) at least $2 \mathrm{~km}$ from the shore to avoid measurement disturbance from land-water transition effects on waveform saturation (Baghdadi et al., 2011).

Next we developed a two step GLA14 data cleaning procedure, close to the one proposed by Zhang et al. (2011). In step 1, each of the 237 GLAS 
ICESat transects was first visualy inspected on time-elevation bivariate plots (Figs. 5-a and 5-b) in order to remove obvious outliers and to verify that the water level was almost constant. Some parts of the transects were accordingly excluded when the mean water level varied or when observations were 'constant' due to i) cloudy episodes with outlier elevations in transect (indicating a difference in elevation of approximately $1000 \mathrm{~m}$ ) (Wesche et al., 2009), ii) the proximity of river outlets. Fig. 2 shows the only example of this phenomenon: the extended transect of 14 June 2005 for Station 21 (Holland station) on Lake Michigan is located near an important river outlet (Fig. 2-a). The transect profile shows the $85 \mathrm{~km}$ elevation profile track that increases in the middle near the outlet, producing an upper water level of approximately $70 \mathrm{~cm}$. In Step 2, for each transect, the median elevation value of the remaining shots was calculated and the shots which were at least 4 meters far from this median value were removed.

\section{Here is located Fig. 2}

\subsubsection{Water level reference data}

The reference lake level data in this study were obtained from 27 of the 52 water level stations located throughout the Great Lakes basin. The selected stations are near (less than $20 \mathrm{~km}$ ) the transect of the GLAS footprints. Eleven stations are operated by the Marine and Environmental Data Service (MEDS) of Canada's Department of Fisheries and Oceans, and 16 stations are operated by the U.S. National Oceanic and Atmospheric Administration (NOAA). Both NOAA and MEDS stations continuously monitor the surface levels of the four lakes at 6 minutes intervals (Braun et al., 2004) with a 
standard deviation of $2 \mathrm{~cm}$ (Hovis et al., 2004).

North American Great Lakes are known to have low tides but are sensitive to short-term water-level fluctuations, such as up to $2.44 \mathrm{~m}$ in approximately 2 hours, caused by wind or storm surges, which are known as seiches (Touchart, 2002). Considering this phenomenon and because the ICESat transect lasts very few seconds and a hydrometric station may have a timing bias of a few minutes, this study analyzed the dispersion of recorded ground measurement (hydrometric station data) in a 6-minute range around transect ICESat times for all stations. This analysis exhibits a constant dispersion for each station of $7 \mathrm{~mm}$ for one standard deviation.

In addition, the geoid model G99SSS used in this study to convert the reference data from ellipsoidal height (WGS84) to orthometric height (NAVD88) has a mean error of approximately $2.5 \mathrm{~cm}$ (Smith and Roman, 2001).

Given that these different sources of uncertainty are independent, they can be summed (in variance). As a result, the computed uncertainty on reference ground data was estimated to $3.3 \mathrm{~cm}$ for one standard deviation $\left(\sigma_{R}\right)$.

\subsubsection{Data consistency}

GLA14 products provide original elevation data with ellipsoidal heights based on the same ellipsoid used by the Topex satellite. The lake level data collected from hydrometric stations are in the International Great Lakes Datum of 1985 (IGLD85). Consequently, data transformations are required in order to conduct a consistent comparison in the same reference frame. GLAS heights and lake level heights were therefore converted to the same vertical datum NAVD88. Two successive transformations are required for GLAS heights: the first converts the Topex ellipsoidal heights to WGS84 
ellipsoidal heigts using the geoid model EGM96; the second transforms the WGS84 ellipsoidal heights to NAVD88 orthometric heights using the geodic model G99SSS. For hydrometric station elevation data, the IGLD85 lake level datum converts to orthometric height NAVD88.

\section{Methods}

\subsection{GLAS water elevation saturation correction}

Some ICESat waveforms exhibit distortions, or saturation events, when the high energy emitted by the laser returns, passes the inadequate automatic gain controls and overloads the detector (Sun et al., 2005). This occurs when the amplitude of the energy returned by a number of 1-ns bins is greater than the threshold function of gain (Urban et al., 2008; Abshire et al., 2005), producing an incorrect elevation. The ICESat science team has developed an analytical saturation correction, also available on the data products. Adding this correction to the elevation is recommended for ice and calm water data, but not over oceans (Urban et al., 2008). Corrections vary between 0 and $1.5 \mathrm{~m}$. For some waveforms, the saturation should be corrected but the method used to calculate the correction coefficient cannot provide a correct value and is marked by '-999.00' flags. Fig. 3 shows some ICESat waveforms obtained across Lake Superior; the saturated waveform is clipped and widened artificially by the returning high energy.

\section{Here is located Fig. 3}

Fig. 4 illustrates an example of elevation transects before and after application of the saturation correction. The saturation correction allows a 
reduction of error bias but does not reduce the error dispersion in the figure.

\section{Here is located Fig. 4}

\subsection{GLAS water elevation estimation at transect scale}

To compute the GLAS water elevation estimate $\hat{Z}_{G}$ and uncertainty $\sigma_{G}$ at the transect scale and considering autocorrelation, we used a statistical framework based on the regional variable and random field theories (Cressie, 1993). In this framework, a GLAS transect is viewed as a temporal block, or a delimited part of a temporal random field $(z(t))$. For each GLAS transect, we developed the usual block kriging process (Wackernagel, 1995, p.77) based on an autocorrelation model, allowing both the estimation of the water elevation $\hat{Z_{G}}$ and its corresponding uncertainty $\sigma_{G}$, at the transect scale.

\subsubsection{Autocorrelation test and modeling}

A GLAS transect is composed from $\left(t_{1} \ldots t_{n}\right)$ and $\left(z_{1} \ldots z_{n}\right)$ series, respectively, where $t$ refers to the laser shot (pulse) time, $z$ to the elevation in the NAVD88 altimetrical system and $n$ is the number of shots in the transect. These series are denoted as $z(t)$ and are considered to be a realization of a stationary temporal random function. We want to infer the main property of $z(t)$, its temporal correlation (autocorrelation), especially the high frequency autocorrelation. When $z(t)$ is stationary, with constant expectation and homogeneous temporal covariance, this inference is possible using the variogram modeling of the field $z(t)$, equivalent to the covariance.

Elevation trend test at transect scale. To ensure a stationary process and reenforce the high frequency autocorrelation test power (Armstrong, 1984), 
a linear trend test is first performed. A linear model $z(t)=m(t)+y(t)$, where $m(t)=a t+b$ is the linear regression of $z$ by $t$, and $y(t)$ are the residuals of this linear regression, is fitted. Using the usual T-test on the coefficient $a$ it is tested if a linear trend is significant.

Next, when the trend tests positively, the initial $z(t)$ field is decomposed in two additive term $m(t)+y(t)$, with $m(t)$ a deterministic trend term and $y(t)$ a term consisting of random residuals. When the trend is negative, the $m(t)$ term disappears and we write $z(t)=y(t)$ for the sake of simplicity. To enable a valid comparison between ground station and GLAS measurements and to avoid natural spatial variations of lake water levels at high spatial frequencies, only transects without linear trends were kept further to compute the GLAS deviations and accuracy.

Autocorrelation significance test. Next, to estimate the autocorrelation of $z(t)$ transect data, an experimental variogram $\gamma(\hat{h})$, with $h$ equal to lag time, is computed on the $y(t)$ data (see Wackernagel $(1995$, p.35) for the usual experimental variogram formulation). This variogram was computed on 16 regular lag times each $62.5 \mathrm{~ms}$ ranging from 0 to $1 \mathrm{~s}$, chosen to obtain numerous shot pairs for an accurate variogram estimation for each lag time $h$. An autocorrelation is considered significant when the experimental variogram graph shows a clear increasing shape from small time differences to large time differences. When the corresponding experimental variogram graph shows a flat variogram, no autocorrelation for this GLAS transect exists. To test the significance of the autocorrelation calculated from the experimental variogram, we used the standard empirical Mantel test (Legendre and Fortin, 1989), which simulates data corresponding to the null hypothesis $H_{0}$ through data permutations, where $H_{0}$ corresponds to the absence of 
autocorrelation (Fig. 5-c). At each permutation of the $z$ data, a corresponding experimental variogram is computed. For numerous replications of the permutations, we obtained a quintile distribution of variograms representing $H_{0}$ for each lag time $h$. The $H_{0}$ acceptance area is thus represented in the variogram graph through a $95 \%$ confidence band of $H_{0}$. In the case of significant autocorrelation, the actual experimental variogram for small values of $h$ is below the $2.5 \%$ quintile of $H_{0}$ (the lower line of the band). Here, we chose to reject $H_{0}$ only when the first variogram point was below the $2.5 \%$ quintile of $H_{0}$.

\section{Here is located Fig. 5}

Autocorrelation modeling. In the case of a significant experimental variogram (Fig. 5-d), we chose to model it with a single spherical model function given by:

$$
\gamma(h)= \begin{cases}n u+(s i-n u)\left(\frac{3 h}{2 r}-\frac{h^{3}}{2 r^{3}}\right) & \text { if } h<r \\ (n u+s i) & \text { if } h \geq r\end{cases}
$$

Using a weighted least-square estimation (Pebesma and Wesseling, 1998), the model parameters nugget $(n u)$, range $(r)$ and sill $(s i)$ were fitted. This was done automatically for all GLAS transects from initial fitting parameters corresponding to a nugget equal to the experimental variogram at a smaller lag time, a sill equal to the maximum value of the experimental variogram and a range equal to the time duration at which the variogram reaches its maxium. After the fitting process, a variogram model $\gamma(h)$ was obtained as shown in the example by the fitted line in Fig. 5-d. 


\subsubsection{Transect water elevation estimation with autocorrelation: block kriging}

For a GLAS transect, when autocorrelation is significant and modeled, a mean value $\hat{Z}_{G}$ for the transect is estimated from transect data $z(t)$ from $\hat{Y}$. The $\hat{Y}$ estimate is computed through a block kriging process of $y(t)$ (Wackernagel, 1995, p.77) using the variogram model $\gamma(h) . \hat{Y}$ is therefore a linear combination of $y(t)$ data with kriging weights $\beta_{i}$ :

$$
\hat{Y}=\sum_{i=1}^{n} \beta_{i} y_{i}
$$

Uncertainty on $\hat{Z_{G}}$ is represented in the block kriging estimation standard deviation $\sigma_{G}$ given by (Wackernagel, 1995, p.77):

$$
\sigma_{G}=\sqrt{\mu_{B K}+\bar{\gamma}+2 \sum_{i=1}^{n} \beta_{i} \bar{\gamma}\left(t_{i}, T\right)}
$$

In this equation, $\mu_{B K}$ is the Lagrange multiplier deduced from the block kriging system, $\bar{\gamma}\left(t_{i}, T\right)$ is the average variogram computed between the sample point $t_{i}$ and all points of the transect $T$ (block) and $\bar{\gamma}$ is the variance

within the transect. In practice, both $\hat{Z}_{G}$ and $\sigma_{G}$ are approximated through the average of gridded points within the considered GLAS transect. We chose a gridding step of $10 \mathrm{~ms}$ here corresponding to $1 / 4$ of the time lag between pulses. Note that $\sigma_{G}$ only depends on the data temporal sampling scheme, not on the elevation values $z$. Consequently, given that the temporal sampling scheme of ICESat data is almost regular, except when outliers are excluded from the initial transect data, $\sigma_{G}$ primarily depends on the transect total duration.

When no autocorrelation is observed for a given GLAS transect $\left(H_{0}\right.$ is accepted), $\gamma(h)$ is a pure nugget effect variogram. In this particular case, 
kriging weights $\beta_{i}$ in equation 2 are all equal and equation 3 is simplified to the common SDOM formulation. Consequently $\hat{Z}_{G}$ equals the arithmetic mean $\bar{z}$ of the values $z_{i}$.

\subsection{GLAS deviations to reference water elevation at transect scale}

For each transect $j$ where no linear trend has been observed, a GLAS estimated value $\hat{Z_{G}}$ having $\sigma_{G}$ Gaussian uncertainty was compared to a reference value $Z_{R}$ having $\sigma_{R}$ Gaussian uncertainty. As GLAS and reference elevations can be considered independent Gaussian random variables, the distribution of the deviations between GLAS and reference water elevations can be assumed also to be of Gaussian distribution $N\left(\mu_{j}, \sigma_{j}\right)$, with $\mu_{j}=$ $\hat{Z_{G}}-Z_{R}$ and standard deviation $\sigma_{j}=\sqrt{\sigma_{G}^{2}+\sigma_{R}^{2}}$.

From these Gaussian deviation distributions obtained for a transect, GLAS deviation statistics (accuracy) were computed at station, lake or Great Lakes scales, by simply averaging the cumulative probability functions of the Gaussian laws $N\left(\mu_{j}, \sigma_{j}\right)$ and computing the resulting empirical deviation distribution (not necessarily Gaussian).

From this empirical distribution, the first (bias) and second (standard deviation) moments were estimated to propose GLAS accuracy statistics.

\section{Results and discussion}

\subsection{Autocorrelation between GLAS shot measurments}

A significant high frequency autocorrelation is observed for 107 transects, i.e. $45 \%$ of the initial 237 transects. No direct explanation is known to the authors for the occurrence of the autocorrelation as shown in Fig. 6, although corrrelated and non-correlated transects look randomly distributed in space (Fig. 6-a), or in time (Fig. 6-b). It does not depend on the overall water 
level (low or high) in the lake (Fig. 6-b). For the transects that do experience significant correlation the 107 fitted variogram models show:

- a $\frac{\text { nugget }}{\text { nugget+sill }}$ ratio ranging from 0.24 to 0.52 with a mean value of 0.4 . This value means that there is in average $40 \%$ of randomness between two consecutive, i.e. very close, shots.

- a range ranging from $0.27 \mathrm{~s}$ to $0.34 \mathrm{~s}$ with a mean value of $0.3 \mathrm{~s}$ (time the variogram model becomes flat at sill value). This range corresponds to the duration of 11 pulses and a distance along the transect of approximately $1.9 \mathrm{~km}$.

\section{Here is located Fig. 6}

\subsection{Autocorrelation explanation}

To explore the physical explanation of the significant autocorrelation observed for $45 \%$ of the GLAS transects, we attributed to each one of the 237 transects i) the environmental parameters from the ICESat data at the transect time (surface temperature, surface humidity and pressure) and ii) the GLA14 instrument parameters (transmitted energy, received energy, gain, incidence angle, laser campaign, transect direction and transect dates according to the beginning and end of each laser campaign (Schutz et al., 2005, table 1, p.2)). To explore relationships between the presence of autocorrelation and these available system or environmental parameters, they were all first considered as potential temporal autocorrelation predictors. We used the multivariate classification tree (CART) method of Breiman et al. (1984) that computes predictor importance that explains autocorrelation by 
using indifferrently quantitative or qualitative predictors. The obtained classification tree in Fig. 7 shows separation between the autocorrelated (1) and non-autocorrelated (0) transects based respectively on the transmitted energy (TE), temperature (temp) and pressure (pressure). This tree explain $68 \%$ of the autocorrelation. These results show that the transmitted energy plays a major role in autocorrelation among all parameters. We thus draw from this analysis that significant autocorrelation occurs when the GLAS instrument transmits low energy which notably occurs at the end of each of three lasers life times, and when bad weather conditions are marked by either lower temperature or lower pressure. These results are consistent with no systematic autocorrelation observed in space or time that could have come from satellite system behaviour.

\section{Here is located Fig. 7}

\subsection{Autocorrelation effect on GLAS water elevation uncertainties at transect scale}

$Z_{G}$ estimates and corresponding $\sigma_{G}$ uncertainty parameters were computed for the 117 transects where no significant trend has been observed. When no autocorrelation is observed for the transect, we used the block kriging process (Equation 2), and if not, we used the Standard Deviation Of the Mean (SDOM). Fig. 8 depicts the distribution of the $\sigma_{G}$ uncertainty parameters for transects as a function of the pulse number composing the transect and the presence or absence of autocorrelation. It appears clearly on this figure that the presence of autocorrelation multiplies the $\sigma_{G}$ uncertainty by 8 on average. As expected, accounting for autocorrelation drastically 
changes the $\sigma_{G}$ estimation, even if the $\hat{Z}_{G}$ values differ only slightly (due to the regular time sampling of GLAS measurements). This usual geostatistical result comes from autocorelation that acts as diminishing the number of data.

Here is located Fig. 8

\subsection{GLAS water elevation deviation distribution}

The GLAS deviation, the difference between the GLAS and reference elevation, is considered as a random variable. The distributions of these deviations were computed for all Great Lakes together, for individual lakes and at station scale. For all Great Lakes, the probability of a GLAS water elevation deviation to be lower than $1 \mathrm{~cm}, 10 \mathrm{~cm}$ and $20 \mathrm{~cm}$ in absolute values is $7.5 \%, 66.8 \%$ and $91.9 \%$, respectively, which seems close to a $N(0,10 \mathrm{~cm})$ value. The $2.5 \%$ and $97.5 \%$ quantiles are $29 \mathrm{~cm}$ and $16 \mathrm{~cm}$, respectively. The expectation of this distribution is $-4.6 \mathrm{~cm}$.

Examples of distributions are depicted in Fig. 9, for all Great Lakes, at lake scale (for lake Erie and lake Ontario), at station scale (for station Erie, Fermi Power, Rochester and Toronto) and at transect scale (transect number $5,8,26,24,88,85,92,90)$. The mix of deviation distributions at the lake scale gives the overall Great Lakes deviation distribution. Normality of deviation distributions is clearly low when downscaling. At station scale, there are various shapes of deviation distribution, non-symetric, with positive or negative pseudo-biases. The mix of these deviation distributions at the station scale, with weights equal to transect numbers for each station of a lake, provides the lake deviation distribution. 
However, these results show that when aggregating numerous data, i.e. transects at the Great Lakes scale, and due to the general Law of Large Numbers, the obtained shapes of deviation distribution become nearly Gaussian. This is not true at the station scale where shapes are asymmetrical and complex. In this latter case, attention must be paid in using common accuracy statistics, especially for dispersion parameters.

\section{Here is located Fig. 9}

\subsection{GLAS accuracy parameters}

The right part of Table 1 summarizes the results of the biases and standard deviations statistics at the Great Lakes, lake and station scales. At the Great Lakes scale, the GLAS deviation bias is $-4.6 \mathrm{~cm}$. In other words, GLAS is slightly underestimating the water elevation on average. The bias values range from $-11.4 \mathrm{~cm}$ to $-2.1 \mathrm{~cm}$ at the lake scale and from $-14.5 \mathrm{~cm}$ to $3.8 \mathrm{~cm}$ at the station scale. The bias found on the stations of the Michigan Lake is the higher in magnitude, reaching up to $-14.5 \mathrm{~cm}$ for Station Kewaunee. A standard deviation of $11.6 \mathrm{~cm}$ was computed at the Great Lakes scale. It varies from $7.9 \mathrm{~cm}$ to $12.9 \mathrm{~cm}$ at the lake scale and from $3.3 \mathrm{~cm}$ to $13.7 \mathrm{~cm}$ at the station scale. The highest standard deviation was found at Station Ludington on Lake Michigan. Bias and standard deviation statistics clearly differ from one lake, or one station, to the next. All these standard deviations must be compared in magnitude with the reference data uncertainties (3.3 cm for one standard deviation) and GLAS water elevation estimate uncertainty at the transect scale (Fig. 8). They are clearly of higher magnitude than the reference data uncertainties but are of the same order 
as the GLAS water elevation estimate uncertainty when autocorrelation is significant.

\section{Here is located table 1}

\section{Conclusions}

This study explored the accuracy of GLAS-ICESat inland water elevation data at various spatial scales with a specific emphasis on uncertainties originating from in situ measurements and impacts of autocorrelation between successive ICESat shots, i.e. at temporal high frequencies. This study also benefited from the pre-processing of the GLAS data with the saturation correction of the GLAS waveforms and spatial filtering to avoid measurement disturbance from land-water transition effects on waveform saturation as previously observed. A set of 237 GLAS transects near the available hydrometric ground stations for four of the Great Lakes of North America was analyzed. A significant autocorrelation between successive shot elevation values was observed for $45 \%$ of the transects. This autocorrelation of an approximately 11 pulses duration seems to occur when a combination of a low transmitted energy from the GLAS instrument and bad weather with low temperature and low pressure occurs. The main consequence of this autocorrelation is a drastic increased uncertainty (by 8 times) of the GLAS water elevation at the transect scale.

After removing the 120 transects where a linear trend was observed and assuming Gaussian uncertainties for both reference data and GLAS data upscaled at the transect scale, we derived empirical distributions on GLAS deviations at the Great Lakes, lake and station scales. At the Great Lakes 
scale, a bias of $-4.6 \mathrm{~cm}$ (underestimation) and a standard deviation of 11.6 $\mathrm{cm}$ were computed on the various shapes of GLAS deviation distributions. However, these statistics were highly variable among the stations.

This study indicates that accuracy statistics computation is highly dependent to the assumptions made on satellite data and reference data as well. These assumptions can highly affect the computed accuracy statistics and conclusion. Even if the impact of the temporal correlation in GLAS raw data was partially smoothed by the reference data uncertainty, this can be crucial when reasoning with few data, such as a small number of transects, at the station scale.

The accuracy results of this study confirm that satellite ranging LIDAR provides data with a decimeter accuracy to monitor water level in inland water for the Great Lakes or a wide river section.

\section{Acknowledgements}

The authors would like to thank the ICESat team and the National Snow

and Ice Data Centre for providing ICESat data and expertise. The authors are very grateful to EADS-Astrium and CNES, which supported this study, and especially to Frederic Fabre from EADS Astrium for his useful advices. The authors also want to thank Carmen Games-Puertas who built several useful tools for ICESat waveforms data extraction during the training period. 


\section{References}

Abshire, J., Sun, X., Riris, H., Sirota, J., McGarry, J., Palm, S., Yi, D., Liiva, P., 2005. Geoscience Laser Altimeter System (GLAS) on the ICESat mission: On-orbit measurement performance. Geophysical Research Letters 32(21) (21), 1-4.

Aladin, N., Crétaux, J., Plotnikov, I. S., Kouraev, A. V., Smurov, A. O., Cazenave, A., Egorov, A. N., Papa, F., 2005. Modern hydro-biological state of the Small Aral sea. Environmetrics 16 (4), 375-392.

Armstrong, M., 1984. Problems with universal kriging. Mathematical geology $16(1), 101-108$.

Atkinson, P. M., Tate, N. J., 2000. Spatial scale problems and geostatistical solutions: A review. The Professional Geographer 52 (4), 607 - 623.

Baghdadi, N., Lemarquand, N., Abdallah, H., Bailly, J. S., 2011. The relevance of GLAS/ICESat elevation data for the monitoring of river networks. Remote Sensing 3 (4), 708-720.

Bailly, J., LeCoarer, Y., Languille, P., Stigermark, C., Allouis, T., 2010. Geostatistical estimation of bathymetric LIDAR errors on rivers. Earth Surface Processes and Landforms 35 (10), 1199-1210.

Bercher, N., 2008. Précision de l'altimetrie satelittaire radar sur les cours d'eau. Ph.D. thesis, AgroParisTech.

Bhang, K. J., Schwartz, F. W., Braun, A., 2007. Verification of the vertical error in C-band SRTM DEM using ICESat and Landsat-7, Otter Tail County, MN. IEEE Transactions on Geoscience and Remote Sensing $45(1), 36-44$. 
Birkett, C. M., 1995. The contribution of TOPEX/POSEIDON to the global monitoring of climatically sensitive lakes. Journal of Geophysical Research 100 (C12), 25,179-25,204.

Birkett, C. M., 1998. Contribution of the TOPEX NASA radar altimeter to the global monitoring of large rivers and wetlands. Water Resources Research 34 (5), 1223-1239.

Birkett, C. M., 2000. Synergistic remote sensing of Lake Chad: Variability of basin inundation. Remote Sensing of Environment 72 (2), 218-236.

Birkett, C. M., Mertes, L. A. K., Dunne, T., Costa, M. H., Jasinski, M. J., 2002. Surface water dynamics in the Amazon Basin: Application of satellite radar altimetry. Journal of Geophysical Research - Atmospheres 107 (D20).

Braun, A., Cheng, K. ., Csatho, B., Shum, C. K., June 2004. ICESat laser altimetry in the Great Lakes. In: Proceedings of the 60th Institute of Navigation Annual Meeting. Dayton-OH, USA, pp. 409-416.

Breiman, L., Friedman, J., Olshen, R., Stone, C., 1984. Classification And Regression Tree. London: Chapman and Hall.

Calmant, S., Seyler, F., 2006. Continental surface waters from satellite altimetry. Comptes Rendus - Geoscience 338 (14-15), 1113-1122.

Chen, Q., 2010. Assessment of terrain elevation derived from satellite laser altimetry over mountainous forest areas using airborne LIDAR data. ISPRS Journal of Photogrammetry and Remote Sensing 65 (1), 111-122.

Chen, Y., Chang, F., 2009. Evolutionary artificial neural networks for hydrological systems forecasting. Journal of Hydrology 367 (1-2), 125-137. 
Chiles, J., Delfiner, P., 1999. Geostatistics: modeling spatial uncertainty. New York: John Wiley and Sons.

Chipman, J. W., Lillesand, T. M., 2007. Satellite-based assessment of the dynamics of new lakes in southern Egypt. International Journal of Remote Sensing 28 (19), 4365-4379.

Cressie, N., 1993. Statistics for spatial data. John Wiley and Sons, Inc., New York.

Crosson, W., Limaye, A., Laymon, C., 2010. Impacts of spatial scaling errors on soil moisture retrieval accuracy at L-band. IEEE Transactions on Geoscience and Remote Sensing 3 (1), $67-80$.

Crétaux, J., Birkett, C., 2006. Lake studies from satellite radar altimetry. Comptes Rendus - Geoscience 338 (14-15), 1098-1112.

Duong, H., Pfeifer, N., Lindenbergh, R., 2006. Full waveform analysis: Icesat laser data for land cover classification. International Archives of Photogrammetry, Remote Sensing and Spatial Information Sciences 36 (Part 7), 30-35.

Harvey, K., Grabs, W., 2003. Expert meeting on hydrological data for global studies, Toronto, Canada. Tech. rep., GCOS/GTOS/HWRP.

Hovis, J., Popovich, W., Zervas, C., Hubbard, J., Shih, H. H., Stone, P., 2004. Effects of hurricane Isabel on water levels. Tech. rep., NOAA / NOS CO-OPS 040.

Jutzi, B., Stilla, U., 2006. Range determination with waveform recording laser systems using a Wiener Filter. ISPRS Journal of Photogrammetry and Remote Sensing 61 (2), 95 - 107. 
Legendre, P., Fortin, M.-J., 1989. Spatial pattern and ecological analysis. Vegetatio 80 (2), 107-138.

Maheu, C., Cazenave, A., Mechoso, C. R., 2003. Water level fluctuations in the Plata Basin (South America) from Topex/Poseidon satellite altimetry. Geophysical Research Letters 30 (3), 43-1.

Mercier, F., 2001. Alimétrie spatiale sur les eaux continentales: apport des missions TOPEX/POSEIDON et ERS1\&2 à l'étude des lacs, mers intérieurs et basins fluviaux. Ph.D. thesis, University Toulouse III, Paul Sabatier.

Morris, C. S., Gill, S. K., 1994. Evaluation of the TOPEX/POSEIDON altimeter system over the Great Lakes. Journal of Geophysical Research 99 (C12), 24,527-24,539.

Pebesma, E. J., Wesseling, C. G., 1998. Gstat: A program for geostatistical modelling, prediction and simulation. Computers and Geosciences 24 (1), $17-31$.

Schutz, B. E., Zwally, H. J., Shuman, C. A., Hancock, D., DiMarzio, J. P., 2005. Overview of the ICESat mission. Geophysical Research Letters $32(21), 1-4$.

Smith, D. A., Roman, D. R., 2001. GEOID99 and G99SSS: 1-arc-minute geoid models for the United States. Journal of Geodesy 75 (9-10), 469490 .

Sun, X., Abshire, J. B., Yi, D., Fricker, H. A., december 2005. ICESat receiver signal dynamic range assessment and correction of range bias due 
to saturation. In: EOS Trans. AGU. Vol. 86 of Fall Meet. Suppl. Abstract G21C-1288.

Touchart, L., 2002. Limnologie physique et dynamique : Une géographie des lacs et des étangs. L'Harmattan, Paris.

Urban, T. J., Schutz, B. E., Neuenschwander, A. L., 2008. A survey of ICESat coastal altimetry applications: continental coast, open ocean island, and inland river. Terrestrial, Atmospheric and Oceanic Sciences 19 (1-2), $1-19$.

Wackernagel, H., 1995. Multivariate Geostatistics. Springer Verlag, Berlin.

Wagner, W., Ullrich, A., Ducic, V., Melzer, T., Studnicka, N., 2006. Gaussian decomposition and calibration of a novel small-footprint full-waveform digitising airborne laser scanner. ISPRS Journal of Photogrammetry and Remote Sensing 60 (2), 100-112.

Wesche, C., Riedel, S., Steinhage, D., 2009. Precise surface topography of the grounded ice ridges at the Ekströmisen, Antarctica, based on several geophysical data sets. ISPRS Journal of Photogrammetry and Remote Sensing 64 (4), $381-386$.

Zhang, G., Xie, H., Kang, S., Yi, D., Ackley, S., 2011. Monitoring lake level changes on the Tibetan Plateau using ICESat altimetry data (2003-2009). Remote sensing of Envrionment 115 (7), 1733-1742.

Zwally, H. J., Schutz, B., Abdalati, W., Abshire, J., Bentley, C., Brenner, A., Bufton, J., Dezio, J., Hancock, D., Harding, D., Herring, T., Minster, B., Quinn, K., Palm, S., Spinhirne, J., Thomas, R., 2002. ICESat's 
laser measurements of polar ice, atmosphere, ocean, and land. Journal of Geodynamics 34 (3-4), 405-445. 


\begin{tabular}{|c|c|c|c|c|c|c|}
\hline Lake & Id & Station & $\begin{array}{l}\text { Number of } \\
\text { shots used }\end{array}$ & $\begin{array}{c}\text { Number of } \\
\text { transects used }\end{array}$ & $\begin{array}{r}\text { Bias } \\
(\mathrm{m})\end{array}$ & $\begin{array}{r}\text { Standard Deviation } \\
(\mathrm{m})\end{array}$ \\
\hline Erie & 1 & Bar Point & 975 & 8 & 0.008 & 0.035 \\
\hline Erie & 2 & Fermi Power & 1634 & 16 & -0.057 & 0.102 \\
\hline Erie & 3 & Marblehead & 198 & 2 & -0.012 & 0.034 \\
\hline Erie & 4 & Cleveland & 607 & 8 & 0.006 & 0.055 \\
\hline Erie & 5 & Fair Port & 240 & 6 & 0.038 & 0.054 \\
\hline Erie & 6 & Erie & 711 & 10 & -0.058 & 0.112 \\
\hline Erie & 7 & Sturgeon & 2148 & 18 & -0.051 & 0.089 \\
\hline Erie & 8 & Port Colborne & 2034 & 16 & -0.012 & 0.093 \\
\hline Erie & 9 & Port Dover & 287 & 5 & -0.044 & 0.051 \\
\hline Erie & 10 & Port Stanley & 782 & 9 & 0.028 & 0.061 \\
\hline Erie & 11 & Erieau & 651 & 18 & -0.038 & 0.059 \\
\hline Erie & & & & Mean & -0.021 & 0.109 \\
\hline Ontario & 12 & Port Weller & 1220 & 14 & -0.097 & 0.092 \\
\hline Ontario & 13 & Rochester & 979 & 14 & -0.031 & 0.084 \\
\hline Ontario & 14 & Oswego & 253 & 5 & -0.140 & 0.034 \\
\hline Ontario & 15 & Kingston & 221 & 5 & -0.033 & 0.038 \\
\hline Ontario & 16 & Cobourg & 1631 & 17 & -0.028 & 0.074 \\
\hline Ontario & 17 & Toronto & 743 & 8 & -0.022 & 0.084 \\
\hline Ontario & & & & Mean & -0.048 & 0.087 \\
\hline Michigan & 18 & Green bay & 213 & 3 & -0.088 & 0.124 \\
\hline Michigan & 19 & Kewaunee & 384 & 4 & -0.145 & 0.056 \\
\hline Michigan & 20 & Calumet & 571 & 7 & -0.143 & 0.128 \\
\hline Michigan & 21 & Holland & 264 & 4 & -0.022 & 0.084 \\
\hline Michigan & 22 & Ludington & 425 & 6 & -0.120 & 0.137 \\
\hline Michigan & & & & Mean & -0.114 & 0.129 \\
\hline Superior & 23 & Ontanagon & 213 & 15 & -0.048 & 0.093 \\
\hline Superior & 24 & Marquette & 384 & 8 & -0.091 & 0.042 \\
\hline Superior & 25 & Ross Port & 571 & 12 & -0.042 & 0.062 \\
\hline Superior & 26 & Thunder Bay & 264 & 5 & -0.004 & 0.087 \\
\hline Superior & 27 & Grand Marais & 425 & 6 & 0.010 & 0.033 \\
\hline Superior & & & & Mean & -0.042 & 0.079 \\
\hline ALL LAKES & & & & Mean & -0.046 & 0.116 \\
\hline
\end{tabular}

Table 1: Left : Number of GLAS shots and transects used across each hydrometric station of the four Great Lakes; Right: biases and standard deviation of deviations (GLASreference) resulting from comparison between ICESat elevations and reference elevations 


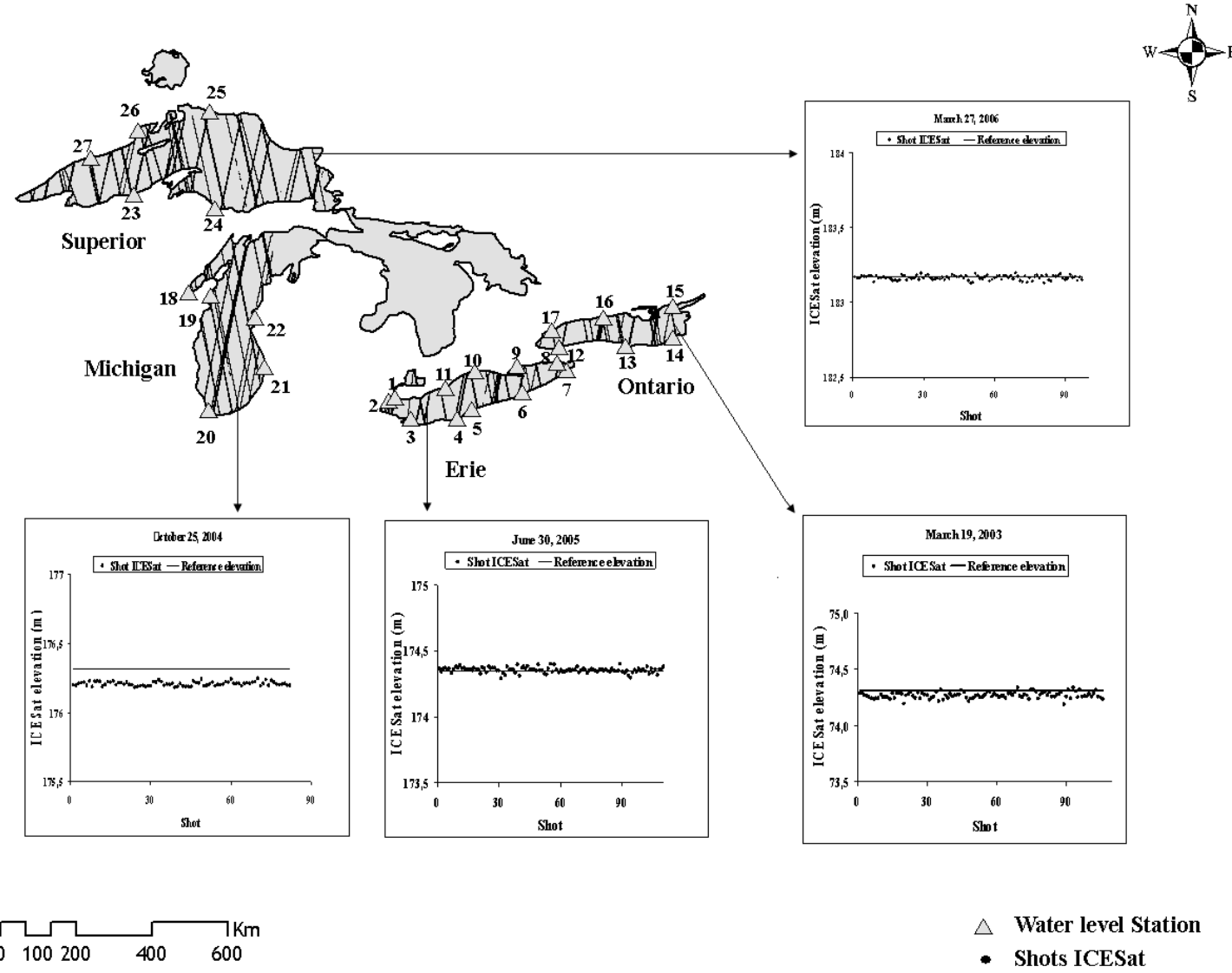

Fig 1: GLAS-ICESat shots forming transects over the Great Lakes and the location of the 27 hydrometric stations. 


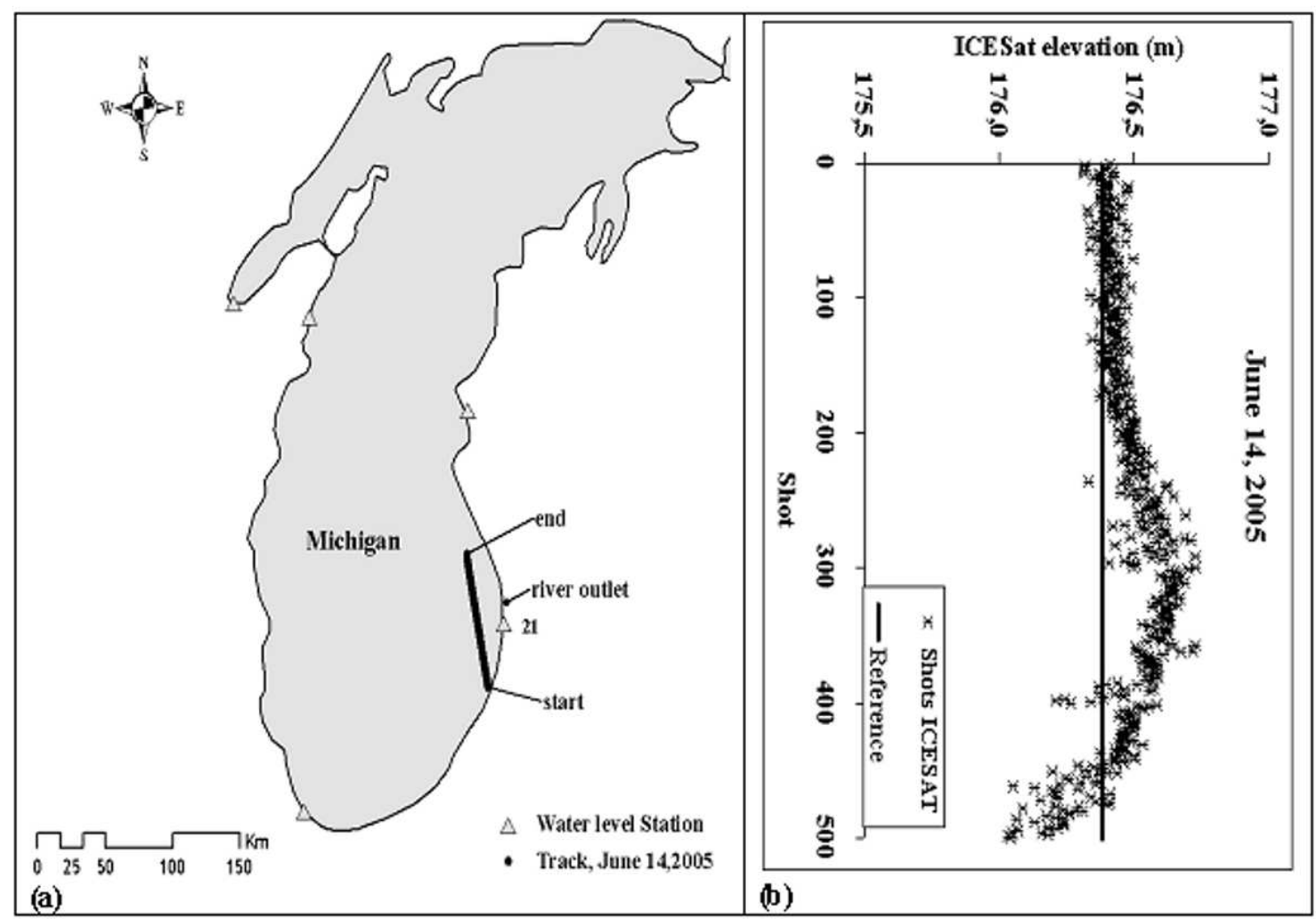

Fig 2: (a) GLAS transect of 14 June 2005 at Holland station (Number 21) on Lake Michigan; (b) the corresponding ICESat elevation profile (with abscissae = shot number) in comparison to hydrometric station data (reference elevation). 


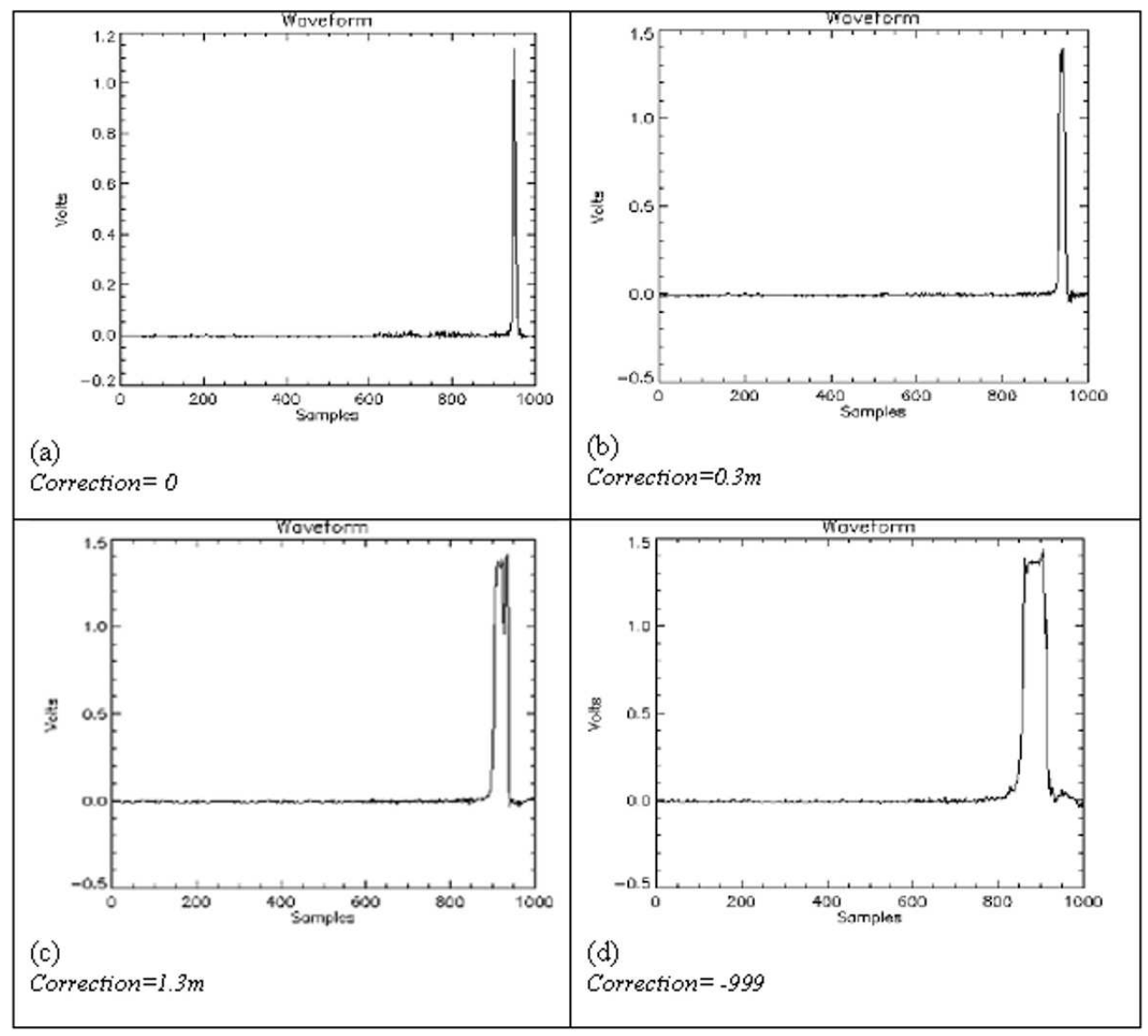

Fig 3: Example of GLAS waveforms on Lake Superior: (a) Unsaturated waveform ; (b) Waveform with low saturation ; (c) and (d) waveforms with high saturation. Ordinate $=$ energy in volts and abscissae $=$ bins number (bins spacing $=1 \mathrm{~ns}$ ). 


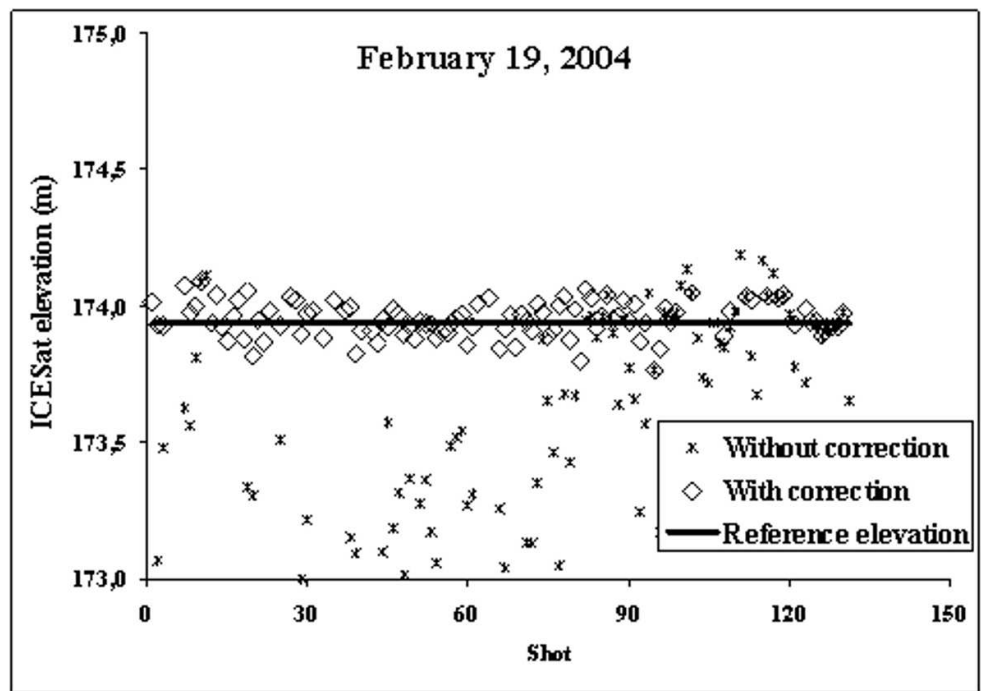

Fig 4: Example of a GLAS-ICESat transect compared to reference elevation. Abscissae $=$ shot number and ordinate $=$ elevation $($ ICESat with and without saturation correction and hydrometric station). 

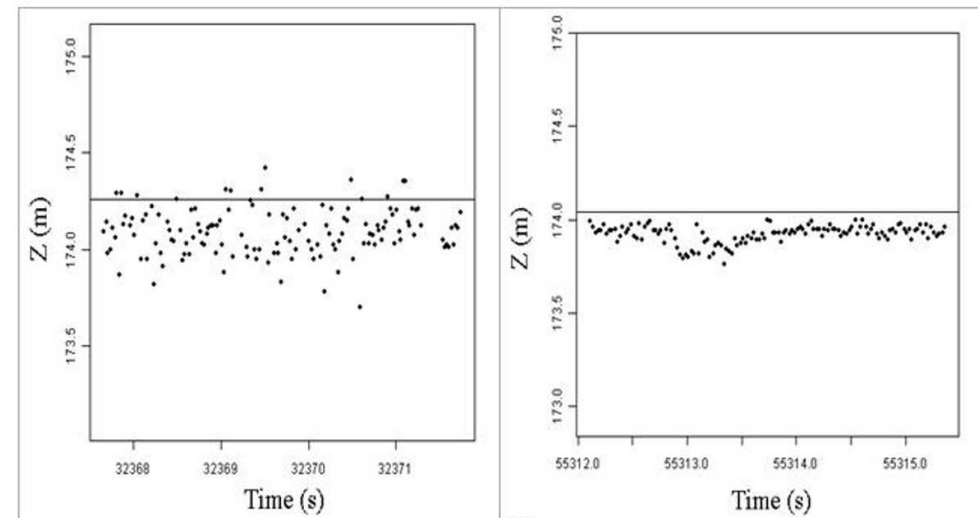

(a)

(b)

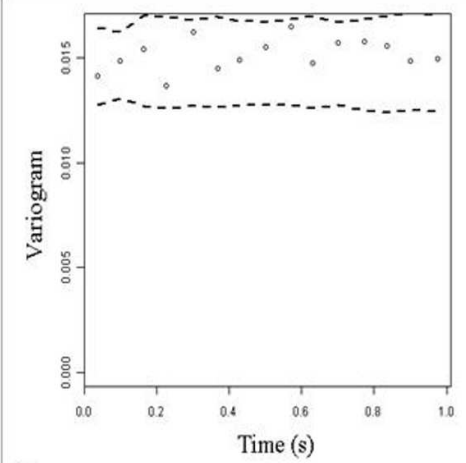

(c)

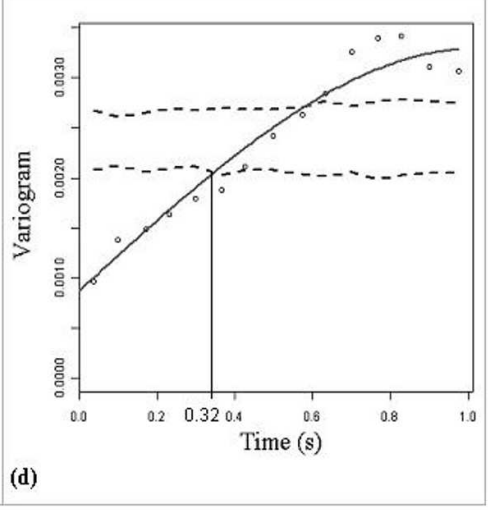

Fig 5: (a) and (b): temporal series $z(t)$, and (c) and (d): corresponding experimental variograms obtained on the transect at Port Colborne station from 2 February 2005 (a, c) and Bar Point station from 10 May 2007 (b, d). The dashed lines in (c, d) represent the two $H_{0}$ envelopes, the straight lines in $(\mathrm{a}, \mathrm{b})$ represent the reference elevation, and the curve lines in $(\mathrm{c}, \mathrm{d})$ are the spherical model function fitted to the experimental variogram (points on $\mathrm{c}, \mathrm{d}$ ). (a, c): absence of autocorrelation. (b, d): significant autocorrelation. (d) Variogram range $=0.32 \mathrm{~s}$. 


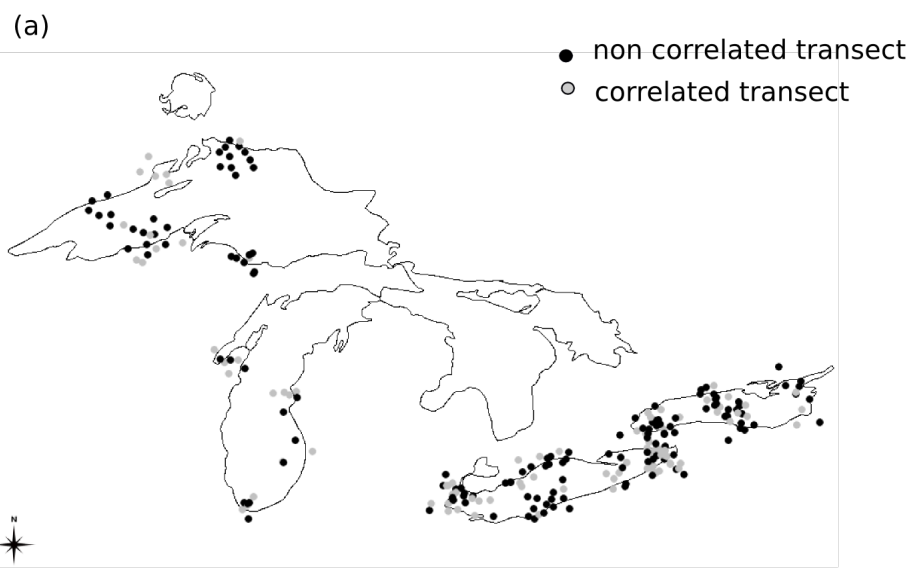

(b)

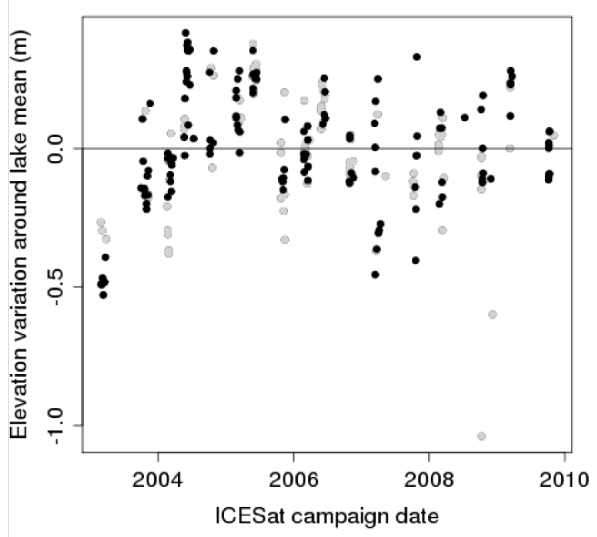

Fig 6: (a) Correlated and non-correlated GLAS transects on the Great Lakes - exact locations of transects have been slightly translated to depict overlapping transects; (b) correlated and non-correlated GLAS transects along the ICESat mission dates - the ordinate is the deviation between the reference elevation of a given lake at each transect date and the mean elevation of the lake calculated using reference elevations for all dates. 
$68 \%$ of classes explained

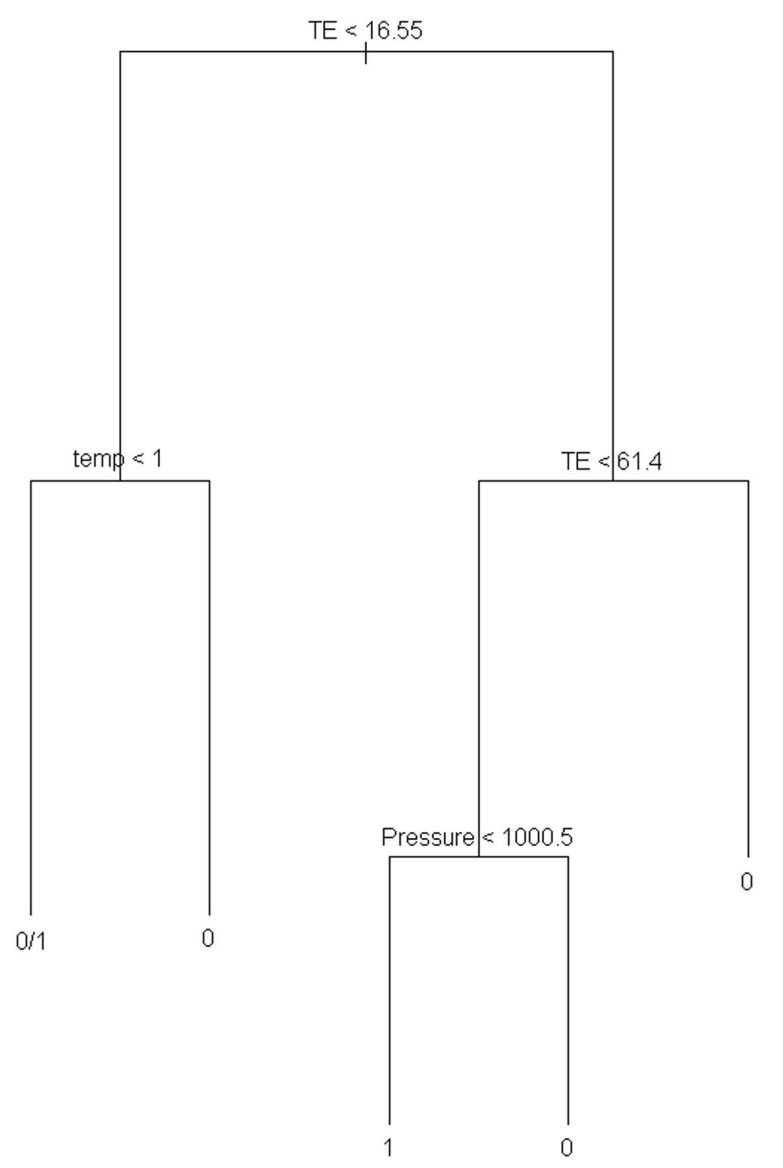

Fig 7: Classification tree explaining the autocorrelation of the transects. A value of 0 on leaves denotes the absence of autocorrelation, and a value of 1 on leaves denotes autocorrelation. The $0 / 1$ value on a leaf means that it mixes correlated and non-correlated transects in equal proportions. 


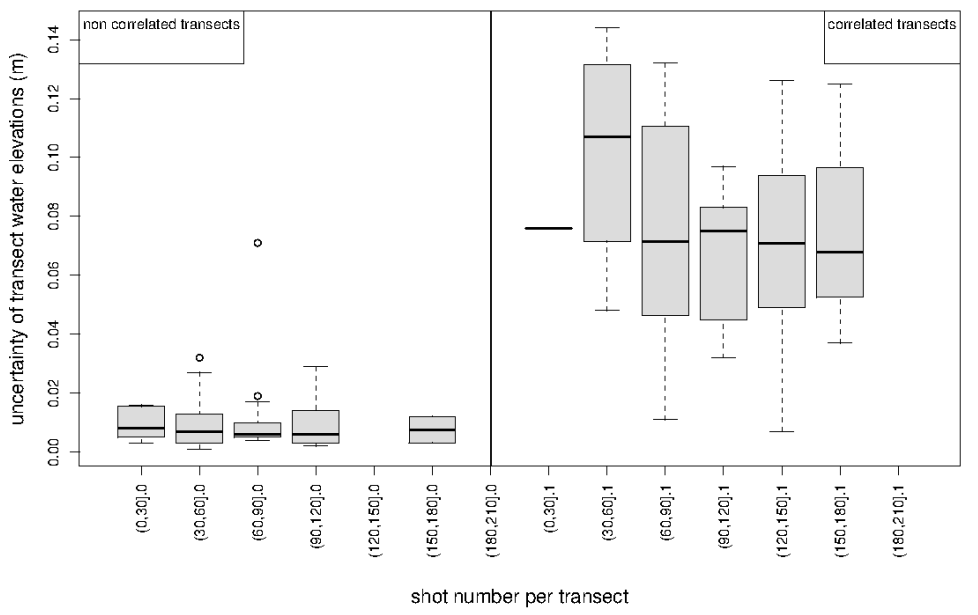

Fig 8: Distribution of the standard deviation $\sigma_{G}$ characterizing the uncertainty of estimated water elevations at the transect scale from GLAS data. This distribution is shown as a function of the shot number composing the transect and presence (right) or absence (left) of autocorrelation. 


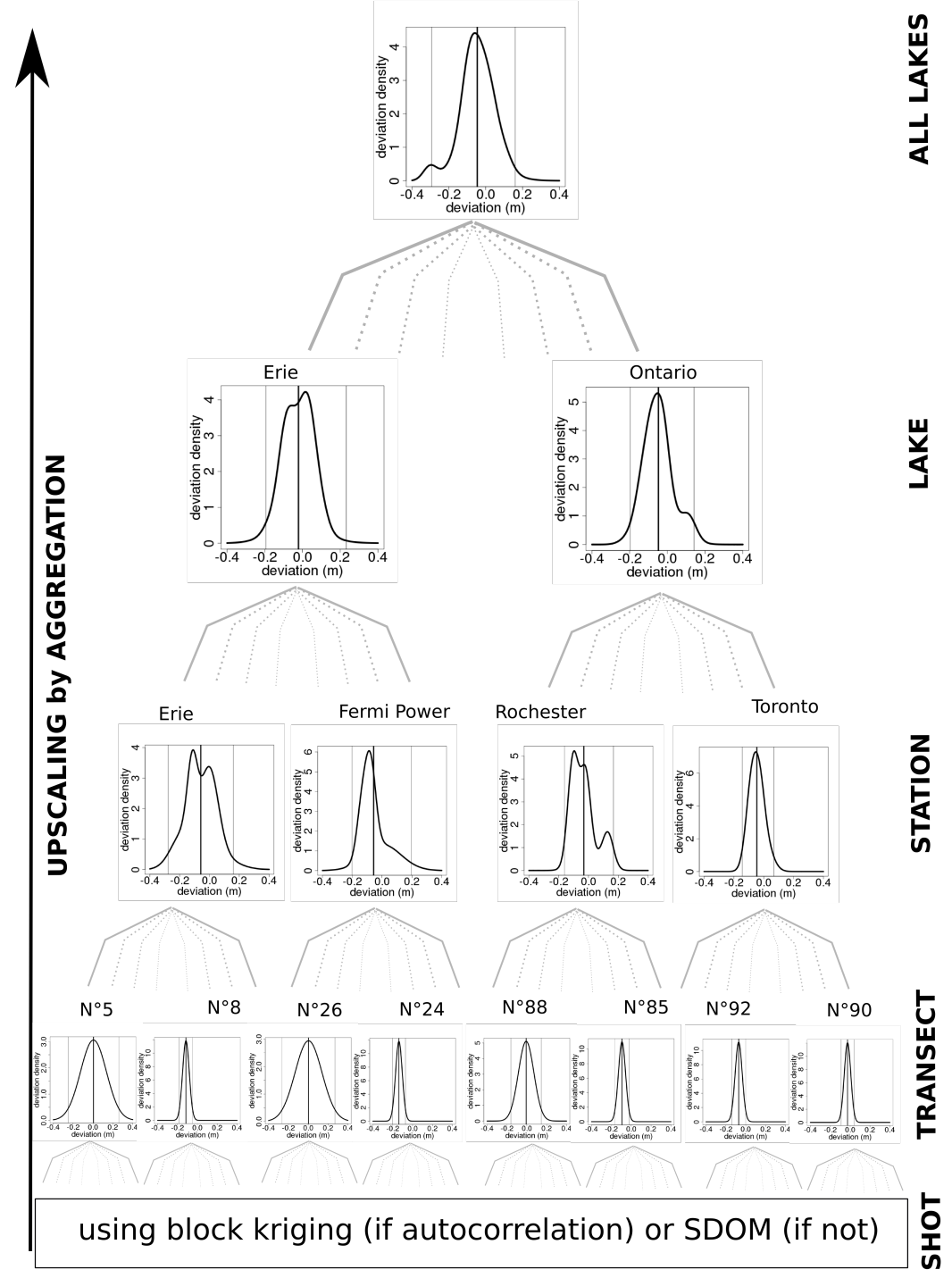

Fig 9: GLAS water elevation deviation distribution and upscaling: For transect scale (down), for station scale, for lake scale and all lake scale (up). Not all distributions for lake, station and transect scales are depicted but only examples. The black wide central line on density plots denote the biases values and the thin lines denotes the $2.5 \%$ and 95.5 $\%$ quantiles respectively. The two examples of deviation distribution selected at transect scale for each lake are for a correlated transect (wide on the left) and a not-correlated transect (thin on the right). 